\title{
A integração das actividades turísticas nas estratégias familiares na Chã das Caldeiras, ilha do Fogo (Cabo Verde)
}

\author{
Vitor Popinsky* \\ Instituto de Ciências Sociais da Universidade de Lisboa (Portugal)
}

Resumo: O presente artigo tem como principal objectivo analisar as actividades turísticas desenvolvidas na Chã das Caldeiras e de como estas têm sido incorporadas na diversidade e na flexibilidade das estratégias familiares que definem o modo de produção doméstico local.

O caso aqui apresentado considera que a incorporação das actividades turísticas com as já existentes deve-se ao tipo de turismo que se desenvolveu na Chã das Caldeiras, na sua maioria devido a factores exógenos, mas também, por aspectos intrínsecos à organização doméstica existente, que em termos das atividades produtivas nos meios rurais, estão condicionadas pela economia do incerto.

Palavras-chave: Turismo sustentável; Estratégias familiares; Economia do incerto; Reprodução social; Modos de produção.

The integration of tourism activities in family strategies in Chã das Caldeiras, Fogo Island (Cape Verde)

Abstract: The main objective of this article is to analyse the tourist activities developed in Chã das Caldeiras and how they have been incorporated into the diversity and flexibility of the family strategies that define the local domestic mode of production.

The case presented here considers that the incorporation of tourism activities with those already existing is due to the type of tourism that developed in the Chã das Caldeiras, mostly exogenous factors, but also by the intrinsic aspects of the existing domestic organization, which in terms of the productive activities in rural areas, are conditioned by the uncertain economy.

Keywords: Sustainable tourism; Family strategies; Economics of uncertainty; Social reproduction; Modes of production

\section{Introdução}

A erupção vulcânica de 1995, que ocorreu na Chã das Caldeiras, é visto pelos habitantes como momento em que se impulsionou o turismo na região. Antes deste fenómeno natural, a agricultura era a principal atividade económica das famílias, mas com aumento da procura turística, outras atividades começaram a despontar, constituindo na altura do meu trabalho de campo ${ }^{1}$, um factor importante na subsistência das famílias da Chã.

Um dos debates em torno do turismo consiste no seu impacto em economias rurais (Milano e Gascón). No caso aqui apresentado iremos mostrar que o desenvolvimento turístico criou novas fontes de rendimento para os grupos domésticos, porém, não existe uma alienação em relação às outras actividades económicas existentes, em vez disso, as actividades turísticas foram integradas na pluriatividade já existente.

A incorporação das actividades turísticas com as já existentes deve-se, por um lado, ao tipo de turismo que se desenvolveu na Chã, pois apesar do aumento de turistas que visitam este lugar, o seu número ainda é incipiente, não permitindo que a maioria dos habitantes se dedique unicamente a este tipo de

Instituto de Ciências Sociais da Universidade de Lisboa. Doutorando em Antropologia no Instituto de Ciências Sociais da Universidade de Lisboa; E-mail: vpopinsky@gmail.com 
actividades. Por outro lado, verifica-se que a pluriatividade está relacionada com a economia do incerto que caracteriza não só esta comunidade, mas também, o meio rural cabo-verdiano em geral.

As recorrentes secas na região e a estrutura agrária baseada no morgadio que se desenvolveu em Cabo Verde, estão na origem desta conjuntura. Com o aumento da população, principalmente de escravos, a importação de alimentos deixou de ser insuficientes. A solução passou pela introdução do cultivo do milho maís, que se tornou alimento base da dieta cabo-verdiana:

Das experimentações feitas em Cabo Verde surgiu o milho maís, trazido da América, o qual se adaptou bem às condições do arquipélago e aos hábitos alimentares dos escravos, desde logo se tornando o elemento básico do regime alimentar cabo-verdiano, facilitando, deste modo, o povoamento e desenvolvimento do arquipélago. (Filho, 1997, 190)

Apesar do cultivo do milho e de outras culturas de sequeiro como é o caso do feijão terem permitido o povoamento e de se tornarem na base alimentar do arquipélago, a subsistência alimentar da população proveniente da produção agrícola do país sempre esteve em risco, mais precisamente por causa das recorrentes secas que caracterizam esta região e que se traduziram ao longo da história do arquipélago em vários períodos de crises e que levaram à morte de muitas pessoas ou então à emigração (Carreira, 1983; 1984).

Para além das limitações climáticas, também se pode questionar as politicas coloniais, como fez Moran (1982) ao justificar que o processo de colonização portuguesa em Cabo Verde consistiu em transplantar produtos que refletissem a dieta alimentar portuguesa, em vez do cultivo de alimentos característicos da região, como é o caso do sorgo ou do milho-miúdo, que se adequam aos níveis baixo de pluviosidade de Cabo Verde.

Não obstante, a agricultura de sequeiro continua a ser o principal tipo de cultura praticada em Cabo Verde e apesar das secas ainda ocorrerem, os períodos de crise extrema deixaram de existir ainda durante o período colonial, evidenciando mais uma vez a importância das politicas e estratégias coloniais, pois, a partir deste período foram implementados planos estratégicos de forma a prevenir as secas:

[...] para minimizar estes problemas em épocas de crise, foram tentadas medidas de emergência que se traduziram em ajudas em termos de trabalhos de apoio (obras publicas) criadas pelo Estado, de modo a empregar a mão-de-obra agrícola, que assim teria dinheiro para adquirir alguns bens necessários à subsistência. (Filho, 1997, 229)

Estas politicas também foram implementadas no pós-independência, mas mesmo com o sucesso alcançado, as crises ainda persistem na mente das pessoas. mas não só, pois os condicionalismos em volta da agricultura, tanto por causa da dependência aos mercados externos em relação aos produtos comercializáveis, como também pelas secas cíclicas, fazem com que até aos dias de hoje as famílias nos meios rurais estejam estruturadas numa lógica da incerteza, isto é:

As condições de produção de subsistências estão assim, ciclicamente, postas em causa num pano de fundo de um ecossistema que dificilmente consegue estabelecer as condições da produção de recursos mínimos e num enquadramento de grande incerteza estrutural, far from equilibrium, numa lógica de "tudo ou nada.

(Couto, 2010, 172)

O processo de reprodução social das famílias da Chã é indissociável desta economia do incerto e por isso mesmo central para entender as atividades turísticas, pois estas dependem das lógicas de vicinalidade e das relações de parentesco existentes, relações estas que permitem aos agentes sociais contornarem as vicissitudes decorrentes dos recursos mínimos existentes.

\section{O turismo como ferramenta de desenvolvimento sustentável}

Em termos económicos, Cabo Verde insere-se nos países designados por Pequenas Economias Insulares (PEI), que de forma geral apresentam aspectos semelhantes entre si, como a pequena dimensão territorial, limitados recursos naturais, estruturas de actividades económicas pouco diversificadas, distanciamento e isolamento geográfico dos centros económicos, capacidade institucional limitada, dependência em relação a fluxos externos instáveis (especialmente as remessas dos emigrantes e da 
ajuda ao desenvolvimento), e com uma grande susceptibilidade à ocorrência de catástrofes naturais e mudanças ambientais (Estêvão, 2001).

Os estudos que seguem esta linha teórica (Bertram, 1999; Watters, 1987) consideram que estas especificidades têm constituído um entrave ao desenvolvimento destas economias, restringido uma grande parte destes Estados a um modelo de desenvolvimento económico habitualmente designado MIRAB: MI- migrações, R- remessas, A- ajuda, B- burocracia e Cabo Verde enquadra-se neste modelo, uma vez que existe uma excessiva dependência nos fluxos externos, que é habitualmente analisada como prejudicial para o desenvolvimento das economias deste tipo:

Este modelo é nefasto pelo facto das emigrações e das remessas não conduzirem necessariamente ao "desenvolvimento sustentável" mantendo pelo contrário a economia "congelada" num estado de baixa produtividade devido aos reduzidos níveis de investimento interno gerados no sector privado além da preservação de um "fácil estilo de subsistência" [...]. (Ferreira, 2008: 76)

Apesar deste entrave, o país tem apresentado resultados económicos positivos, tendo em 2008 passado a ser o único país africano, a par do Botswana, a conseguir alcançar a categoria de Países de Desenvolvimento Médio (Baker, 2009).

Um dos principais factores para o crescimento económico deste arquipélago africano está relacionado com a indústria do turismo, que se tornou nos últimos dez anos na principal fonte de riqueza e crescimento económico e que é já considerada o "petróleo" do país (Carvalho, 2007; Santos, 2008). Esta analogia entre o turismo e o petróleo, que é constantemente proferida pelos cabo-verdianos, tem todo o cabimento. Da mesma forma que o petróleo representa a principal fonte de riqueza e de desenvolvimento para alguns países, o turismo em Cabo Verde tem exercido esse papel, levando o governo a considerá-lo como "um sector estratégico e prioritário enquanto factor de desenvolvimento do país. Em Cabo Verde o turismo constitui a principal fonte de riqueza nacional, representando cerca de $20 \%$ do PIB, e é um sector para o qual se canalizam mais de 90\% dos investimentos externos" (Santos, 2009: 1). Outra similaridade que está na base da identificação metafórica do turismo com o petróleo prende-se com os impactos negativos que ambos apresentam e que têm movimentado inúmeros debates a vários níveis.

Uma área de investigação muito associada aos debates em torno do turismo são os estudos de desenvolvimento (Santos, 2009; Kadt, 1979; Crick, 1989; Urry, 1990). A origem do conceito moderno de desenvolvimento remonta ao discurso proferido pelo presidente norte-americano Truman em 1949 (Gardner e Lewis, 1996), que estabelece que os benefícios dos avanços tecnológicos e do progresso industrial das sociedades desenvolvidas deveriam ser utilizados para melhorar e desenvolver as sociedades subdesenvolvidas. Nesta primeira fase, o conceito de desenvolvimento estava estritamente relacionado com o crescimento económico e com as teorias da modernização.

Durante a década de 1980 assistiu-se a uma viragem em torno da temática do desenvolvimento, com a introdução do conceito de sustentabilidade, que foi apresentado em 1987 pela comissão Bruntland no relatório "Nosso futuro comum". Definiu-se aí o desenvolvimento sustentável como o "desenvolvimento que atende às necessidades do presente sem comprometer a possibilidade de as gerações futuras atenderem suas próprias necessidades" (Redclift, 2008: 279).

Este novo paradigma, que surgiu como a tábua de salvação do desenvolvimento, tornou-se também numa buzzword, uma vez que se disseminou nos mais distintos meios. O turismo não foi excepção (Pelling, 2008), pois o conceito de turismo sustentável converteu-se no lema unanimemente aceite e difundido tanto por meios académicos e organizações internacionais, como também pelas autoridades governamentais e ONGs, sendo considerado actualmente como o discurso mais recorrente sobre turismo (Higgins-Desbiolles, 2010). Não obstante, e apesar das grandes potencialidades que o turismo sustentável pode criar e de perspectivar um futuro mais promissor para as próximas gerações, o conceito em si mesmo tem desencadeado vários discursos que muitas vezes são antagónicos, sendo considerado como uma forma de ideologia, um slogan político e, dependendo do contexto em que é utilizado, um conceito, uma filosofia, um processo ou um produto (Wall, 1997).

A definição mais amplamente difundida de turismo sustentável baseia-se na estabelecida pela Organização Mundial do Turismo:

Turismo ecologicamente suportável no longo prazo, economicamente viável, assim como ética e socialmente equitativo para as comunidades locais. Exige integração no meio ambiente natural, cultural e humano, respeitando o frágil balanço que caracteriza muitos destinos turísticos, em particular pequenas ilhas e áreas ambientalmente sensíveis. (Lu e Nepal, 2009: 6) 
Em termos teóricos as posições também oscilam. Estas divergências estão bem mencionadas na abordagem cronológica feita por Clarke (1997), que divide os estudos sobre turismo sustentável em três posições. A primeira abordagem, designada dos pólos opostos, considera o turismo sustentável em oposição ao turismo de massas, sendo o primeiro conotado como positivo e o segundo como negativo. A segunda abordagem, denominada de contínuo, deu-se no início da década de 90. Nesta fase, o turismo sustentável e o turismo de massas deixam de ser vistos como opostos, uma vez que se verifica que mesmo o turismo sustentável se pode tornar insustentável. A última posição descrita por Clarke é a da convergência e basicamente considera o turismo sustentável como uma meta que todo o tipo de turismo, independentemente da sua escala, deve esforçar-se por alcançar.

A expansão do turismo em Cabo Verde apresenta formas heterogéneas de ilha para ilha, o que torna este país especialmente aliciante para os estudos de turismo (Ferreira, 2008). Comparando o turismo na ilha da Boavista com o seu desenvolvimento na ilha do Fogo, verificamos que no primeiro caso encontramos um turismo de massas, onde os atractivos se baseiam no usufruto de sol e da praia, enquanto que na ilha do Fogo, o turismo tem crescido em menor escala e enquadra-se no denominado turismo de natureza, constituindo o vulcão o principal atractivo turístico. Estas diferenças relacionam-se com os tipos diferenciados de turistas que procuram estas ilhas, e também com as estratégias e os actores sociais envolvidos nesta actividade.

Por estas razões, torna-se pertinente analisar o impacto que o turismo tem exercido sobre a comunidade da Chã das Caldeiras e em especial na organização familiar, pois apesar de a ilha do Fogo não ter um crescimento turístico à escala do da ilha da Boavista, constata-se que esta actividade tem alterado o modo de vida dos habitantes desta comunidade.

Algumas mudanças decorrentes do crescimento turístico na ilha da Boavista, são abordadas por Lobo (2006) ao nível da vida familiar. Embora o seu trabalho se centre na relação entre emigração feminina e a organização familiar naquela ilha, a autora dedica o último capítulo "Novos tempos, novos atores, novas famílias") aos impactos provocados pelo boom turístico na esfera doméstica. Lobo começa por destacar os impactos que o turismo tem produzido entre os jovens locais, pois a expansão desta atividade tem criado mais oportunidades de trabalho, o que permite aos jovens fixarem-se por mais tempo na ilha, invertendo assim a tendência anterior de saída para o exterior. Para além disto, a maior demanda de mão-de-obra provocada pelo turismo tem originado a imigração de novos atores sociais que, ao contrário do comum turista, se fixam na ilha. Dentro destes novos atores sociais, encontram-se aqueles que estabelecem relações conjugais com os locais, mas que "entram em conflito com o modo local de perceção do que é a família" (Lobo, 2006: 230).

Como iremos analisar de seguida, as atividades turísticas desenvolvidas na Chã das Caldeiras estão condicionadas por factores externos à população, mas está não pode ser considerada como passiva - povo facilmente "aculturável - pelo contrário, as intervenções externas são muitas vezes contestadas, mais ainda, as alterações sociais que advêm das atividades turísticas são incorporadas na diversidade e na flexibilidade das estratégias e lógicas familiares que definem o modo de produção doméstico na Chã das Caldeiras.

\section{O turismo na Chã das Caldeiras}

A Chã das Caldeiras é uma aldeia situada no sopé do cone principal do vulcão Pico do Fogo, na ilha do Fogo, uma das nove ilhas habitadas do arquipélago de Cabo Verde. As características geográficas desta aldeia constituíram um factor central no desenvolvimento peculiar das actividades económicas e sócio-culturais que caracterizam esta comunidade, distinguindo-a das restantes, tanto ao nível da ilha do Fogo como também a nível nacional. Como escreveu Orlando Ribeiro na década de 1950:

A Chã constitui um caso especial, que merece ser estudado à parte. Existe aí uma povoação, encerrada no hemiciclo e mais perto da Bordeira, formada por dois núcleos separados pelo degrau que travessa transversalmente a depressão; o menor é o mais elevado (Portela $1650 \mathrm{~m}$ ); o maior (Bangaeira) fica umas dezenas de metros abaixo. No conjunto formarão duas dúzias de casas, a que podem corresponder pouco menos de um cento de habitantes [...] A população vive em grande isolamento, cultivando os taludes de escombros na base da Bordeira e uma faixa de terra compreendida entre esta e os campos de lava recentes [...] A povoação fica assim completamente separada dos outros lugares habitados, que se encontram 600 a $700 \mathrm{~m}$ abaixo dela e algumas horas a caminho a pé ou a cavalo. (Ribeiro, 1998: 140-141) 
Os solos férteis, o clima húmido e a abundante água existente na Chã das Caldeiras permitiram o cultivo de produtos agrícolas que não existem nas outras ilhas de Cabo Verde, como é o caso das videiras e certas árvores de fruta, sendo que a agricultura representa a principal actividade desta comunidade (República de Cabo Verde, 2009).

Apesar destes aspectos divergirem do panorama nacional, existem outros que se assemelham, como é o caso da emigração. No caso da ilha do Fogo, o inicio do seculo XIX marca o período em que alguns habitantes partiram nos navios baleeiros para os Estados Unidos da América (Meintel, 1984) e cujos sucessores continuam a contribuir para a economia dos seus lugares de origem:

Uma grande parte da população local (24\%) depende das remessas dos familiares no estrangeiro. Mas mais do que isso, os emigrantes, com os investimentos na agricultura e construção civil, criam empregos para as famílias do mundo rural e não só” (República de Cabo Verde, 2009: 60).

Em contrapartida, a emigração tem sido na sua maioria masculina, levando a que um número elevado dos agregados familiares (40\%) seja chefiado por mulheres (República de Cabo Verde, 2009). Os dados estatísticos relativos à organização familiar referem que as 120 famílias existentes na Chã das Caldeiras, "são constituídas em média por 6 pessoas, havendo algumas famílias com até 20 pessoas. Muitas vezes existem relações poligâmicas" (República de Cabo Verde, 2009: 56). É voz corrente que a "poligamia", mais informal no resto do arquipélago e mesmo nas outras povoações da ilha do Fogo, é praticada às claras na Chã das Caldeiras.

Para além da agricultura e das remessas enviadas pelos emigrantes, nos últimos anos as actividades associadas ao turismo têm criado fontes de rendimento para as famílias das Chã das Caldeiras, por exemplo com o turismo de habitação, o trabalho como guia turístico, a venda de artesanato, etc. (Expresso das Ilhas, 2009). O turismo na Chã das Caldeiras pode ser enquadrado no chamado "turismo de natureza", o que se reflecte na origem e no tipo de turistas. Estes são na sua maioria "turistas nacionais, provocados essencialmente pelo fenómeno da emigração, seguidos pelos alemães e pelos franceses, contrariando um pouco a lógica da procura no país que é liderada pelos portugueses e pelos italianos" (Bronze, 2007: 58).

A erupção vulcânica de 1995 constituiu o ponto de viragem em relação ao turismo, isto porque, o fenómeno natural trouxe uma maior visibilidade internacional desta ilha, tornando o vulcão activo um produto turístico diferenciador em relação às ofertas dadas nas outras ilhas do arquipélago, sendo utilizado como chamariz pelas agências turísticas e outras meios de comunicação, como é o caso da revista Fragata, disponível abordo dos aviões da TCAV, que num dos seus números refere assim sobre a erupção de 1995 e as diferentes sensações que a escalada ao vulcão pode provocar:

Apesar do tempo transcorrido [da erupção de 1995], a primeira coisa que assalta os sentidos é o forte cheiro a enxofre que ainda emana das profundezas da cratera e a diversidade de cores que os minerais expelidos apresentam.

A brisa fresca que corre convida ao descanso, mas a iminência do perigo, provocado pela instável condição do terreno, pela imensidão do abismo e pelas bermas escarpadas da caldeira, coloca em alerta todos os sentidos, ocupados em evitar um passo em falso que pode ser fatal.

A descida, aparentemente mais fácil, transforma-se no Cabo das Tormentas se se resolve fazê-la pelo lado que as lavas escolheram no seu inexorável caminho para a planície, durante a última erupção. (Rodrigues, 2010:26)

O turismo também foi um dos factores que levou ao retorno das pessoas à Chã após a erupção de 1995. Com a erupção os habitantes tiveram de ser evacuados, tendo o governo construído novas habitações noutras localidades da ilha e interdito o seu regresso, entretanto surgiu um boato na qual a proibição das pessoas voltarem estava relacionada com o interesse de aí ser construído um resort turístico com investimento exterior, situação que motivou o regresso das pessoas.

O retorno coincidiu com o aumento de turistas a visitar a cratera, que em termos estáticos "estima-se em 900 o número de turistas que em 1997 visitou o vulcão e Chã das Caldeiras. No ano de 2000, este quantitativo aumentou para 3000" (Leyens, 2002: 44). Curiosamente, as pessoas da Chã consideram que esta mudança se deveu à chegada de um francês ${ }^{2}$, chamado Patrick, que foi quem construiu a primeira pensão na Chã. Nessa altura as pessoas tinham receio que a construção da Pedra Brabo poderia monopolizar a oferta de alojamentos da Chã, tendo mesmo existido alguma contestação, mas o que aconteceu foi o oposto, pois com a abertura da pousada Pedra Brabo chegaram mais turistas, mas 
como não tinha capacidade para albergar todos os turísticas, as pessoas começaram a construir ao lado das suas casas quartos com casas de banhos para albergar os turistas. É também em torno da Pedra Brabo, que alguns jovens começaram a exercer a atividade de guia turísticos de forma mais consistente, diferenciando-se dos demais, isto porque, com o aparecimento deste estabelecimento um grupo de jovens começou a ter acesso mais fácil aos turistas, pois o proprietário deixava que estes entrassem na Pedra Brabo e oferecessem os seus serviços de guia aos turistas, enquanto que outros teriam de ter a sorte de encontrar os turistas a passear tanto em S. Filipe como na Chã e então negociar a subida ao vulcão. No segundo dia, após a minha chegada a S. Filipe passei por uma experiência deste tipo, pois estava a explorar o centro da cidade, quando um jovem veio ter comigo e começou a falar ou a tentar comunicar comigo em inglês, mas ao explicar que poderia falar em português, lá conseguimos nos entender melhor e aí ele explicou que era guia e que me poderia levar a conhecer o vulcão. Eu agradeci, mas recusei, explicando que iria viver durante um ano na Chã e que de certeza iria escalar o vulcão, mas não naqueles dias. Durante o trabalho de campo encontrei mais vezes este jovem, tanto em S. Filipe como na Chã, acompanhado por turistas, mas o facto de ele não ser da Chã, as suas atividades como guia na Chã poderiam trazer problemas, pois na altura do trabalho de campo, os guias da Chã estavam a formar uma associação de guias locais com o apoio do Parque Natural do Fogo (PNF), que tinha entre os seus objetivos travar a entrada de guias que não pertenciam à comunidade de fazerem excursões dentro da Chã, principalmente os que trabalhavam para as agências de turismo. A criação da associação de guias demonstra como a população se apropria dos discursos de desenvolvimento sustentável para seu proveito, neste caso é a criação de políticas que permitam os residentes obterem benefícios em relação às pessoas de "fora".

Apesar do PNF estar de acordo com os guias locais em limitar as excursões feitas por guias de fora, existem outros aspectos relacionados com o turismo que têm trazido conflitos entre a comunidade e o PNF, que em termos de análise fazem com que a Chã constitua um contexto propício para analisar a relação existente entre o turismo e os discursos divergentes sobre desenvolvimento sustentável. Por estar numa área protegida, a Chã está sobre a alçada do PNF, que tem como principal estratégia a promoção do desenvolvimento sustentável:

Em 2020 o Parque Natural do Fogo e Chã das Caldeiras contribuirão de maneira significativa e sustentável na economia do Fogo, concentrando-se sobre uma oferta de turismo natural de alta qualidade, na produção agrícola e a pecuária, visando a autosu ciência e a exportação de produtos seleccionados de alto valor. A população residente está bem preparada para participar na utilização sustentável dos recursos naturais e turísticos. Os serviços públicos em concertação com a Gestão do Parque garantem a participação igualitária da população residente na economia da ilha, a qualidade e ainda condigna assim como a sua segurança e a dos seus visitantes. (República de Cabo Verde, 2009: 268)

O turismo está integrado nestas estratégias que fomentam o desenvolvimento sustentável e tanto o PNF como também o governo local têm tomado medidas para melhorar as infra-estruturas, como também para preservar alguns aspectos da vida local que consideram essenciais para o turismo, mas que muitas vezes entram em colisão com o que a população local aspira. A estrada asfaltada entre S. Filipe até ao início da cratera como também o facto da Chã ser das poucas localidades da ilha do Fogo em que a eletricidade ainda não chegou, constituem dois exemplos destas divergências, assuntos que remente também para um tópico incontornável dos estudos sobre turismo, ou seja, o de autenticidade (Santos, 2009).

O facto da primeira estrada asfaltada na ilha ter sido construída desde S. Filipe até ao inicio da Chã, demonstra bem a importância que o governo tem dado ao turismo, pois só assim se compreende a prioridade dada a esta via de comunicação que favorece diretamente a comunidade da Chã em detrimento de outras que poderiam ligar as sedes dos municípios e que em termos populacionais são de maior dimensão, como é o caso de S. Filipe/Mosteiros ou S. Filipe/Cova Figueira. Apesar da estrada ter trazido melhorias para a população, as pessoas contestam o facto de esta acabar no início da Chã e que os poucos quilômetros de estrada que faltam até chegar a localidade da Portela estar em más condições e em vez de asfalto ser calcetada, provocando desgastes desnecessários para os veículos que circulam dentro da cratera. Na entrevista que tive com o diretor do PNF falamos sobre este assunto e a sua opinião revela o problema em se colocar asfalto na cratera, ou seja:

Há boas estradas feitas de calçada e é possível fazer, mantendo aquele aspecto humano, porque eu... A imagem que normalmente eu tenho, não sei se todas as pessoas têm a mesma imagem, mas quando se 
vê alcatrão e grandes prédios e coisas do género, uma pessoa pensa logo em trabalho de máquina. Quando se tem calcetamento e casas de pedra e coisas do género, as pessoas já começam a pensar numa coisa mais humana, mais naturalizada. Então, nós é neste perspectiva que defendemos o calcetamento, em vez do asfaltamento.

A mesma perspectiva se coloca com a instalação da electricidade, que foi prometida aos cidadãos da Chã em vários períodos eleitorais, mas que até ao momento do trabalho de campo ainda não tinha sido cumprida. Da mesma forma que a estrada, a instalação da electricidade na Chã das Caldeiras está obstruída pelo impacto visual que os postes de electricidade podem trazer para a cratera, mais ainda, existe o receio de se perder o aspecto "natural" das noites que se pretende dar os turistas, pois com a luz eléctrica nas casas e nas ruas existe o receio de esta alterar a paisagem noturna, onde a luz ainda provem somente da lua e das estrelas. Curiosamente, são os estabelecimentos que recebem turistas que têm geradores, mas que só são ligados quando têm turistas, ficando nas noites sem turistas sem luz como as outras casas da Chã.

Outra instituição externa a ter em consideração é a COSPE, uma ONG italiana, que teve um papel importante no aumento da produção vinícola, mas outra vertente do seu projecto foi na área do turismo, ou seja:

Melhoramento dos produtos locais e dos serviços turísticos oferecidos, definições e regulamentações de um turismo rural respeitoso do ambiente natural e das culturas locais, e, portanto, promoção de uma imagem mais convidativa, que em última analise é, além das localidades especificas envolvidas no projecto COSPE, a imagem complexiva da ilha de Fogo. (Rodrigues e Fattori, 2008: 36)

Em termos práticos, as atividades desenvolvidas por esta ONG foram várias e de forma geral trouxeram benefícios para a população local, como foram as formações dadas aos guias turistas, aos artesãos e também as pessoas que tinham quartos para alugar a turistas. Todavia, existiram outras atividades que até começaram bem, mas que no final trouxeram conflitos entre as pessoas da Chã, como é o caso da Chãtour e da construção do Sirios, a primeira foi uma associação criada pelos habitantes da Chã interessados no sector turístico, que teve o apoio da COSPE e a segunda, uma unidade hoteleira feita pela $\mathrm{ONG}$, onde os lucros obtidos iriam ser divididos pela comunidade. O problema surgiu com a direção que ficou a cargo da associação de vinicultores, mas que os lucros nunca foram divididos pela população. Ao contrário do caso da Pedra Brabo, que no início as pessoas tinham receio, mas que depois obtiveram partido desta unidade hoteleira, no caso do Sirios, aconteceu o inverso, pois o principal objetivo era o de divulgar as diferentes ofertas de hospedagem existentes, tendo sido criado uma página de internet, onde uma pessoa poderia fazer a sua reserva de um quarto, podendo escolher ficar na aldeia turística ou em casa de uma pessoa, mas no final, este tipo de alojamento familiar foi tirado do website, ficando a escolha da reserva de alojamento limitada ao Sírios.

Os vários casos apresentados até ao momento permitem constatar que as atividades turísticas desenvolvidas na Chã das Caldeiras foram, deste o seu inicio, condicionadas por factores externos, mas mesmo quando são impostas, a comunidade utiliza meios para contornar o que acha contraproducente para os seus interesses, chegando mesmo a adaptar os conceitos de desenvolvimento sustentável a seu favor, ou seja, as estratégias utilizadas pela comunidade demonstram como está não é meramente uma receptora-passiva das intervenções externas, pelo contrario, os estímulos externos tornam-se recursos manipuláveis que geram dinâmicas de interconhecimento entre as duas partes, isto porque:

qualquer configuração desenvolvimentista põe sempre em jogo distintas "comunidades epistémicas": dum lado os camponeses, como gestores de recursos mínimos e de pertença familiar, e, do outro, técnicos e consultores das agencias de desenvolvimento internacionais, como modelizadores de "realidades" sociais. Os actores em confronto posicionam-se numa plataforma de interconhecimento, produzindo discursos estratégicos e processos de interacção de conotação politica. A confrontação é intercultural e cognitiva. (Couto, 2010: 398)

É desta confrontação que surgem as alterações sociais produzidas pelas atividades turísticas, mas como no desenvolvimento da cultura vinícola que também teve influencia de instituições externas, constata-se que as atividades turísticas desenvolvidas na Chã das Caldeiras se adaptaram ao modo de produção já existente, estando assim, incorporadas na diversidade e na flexibilidade das estratégias e logicas familiares que definem o modo de produção domestico na Chã das Caldeiras. 
Um dos aspectos turísticos que a comunidade não consegue controlar, isto apesar de poder melhorar os serviços prestados e de fazer com que alguns turistas retornem mais do que uma vez, é o da afluência de turistas, que no caso da Chã das Caldeiras é crucial para compreender como as atividades turísticas têm reforçado o sistema de produção existente, em vez de o enfraquecer como acontece em muitos casos (Kadt 1979; Smith 1989; Cole 2007).

Em termos estatísticos podemos constatar que a ilha do Fogo é a sexta ilha com o maior número de hóspedes, tendo em 2006 o número correspondido a 4038. Este número não se compara com os 167.222 que se hospedaram na ilha do Sal, mas aqui, o alojamento é feito nos grandes resorts que pertencem a investidores estrangeiros, enquanto que na Chã, os alojamentos são feitos nas casas das famílias (a pensão Pedra Brabo é a exceção) e por isso os lucros vão diretamente para os donos das casas que albergam turistas. Apesar disto e da afluência de turistas ter tendência a aumentar, o número de turistas que visitam a Chã das Caldeiras não permite que a maior parte da população da Chã viva unicamente das atividades turísticas, situação que fica explicita no perfil dos turistas, ou seja:

A maioria dos turistas são turistas que podem ser classificados como "turistas interessados no turismo da natureza e da cultura" ou turistas que realizam excursões diárias a partir das ilhas de praia, designadamente do Sal e da Boavista. Aquele primeiro tipo de turista fica cerca de 3 dias no Fogo; em casos muitos raros é que visita apenas a ilha do Fogo. (Leyens, 2002:44)

Para além da dependência em relação às outras ilhas e de uma grande parte dos turistas só fazer visitas de um dia na Chã é preciso ter em conta as oscilações da afluência turística, pois como noutros lugares turísticos, na Chã também existe uma época alta, entre dezembro e janeiro, período este que pode levar a uma sobrelotação dos alojamentos existentes, que fazem com que algumas destas casas tenham de negociar com familiares ou amigos para que estes cedam as suas casas ou quartos para albergar alguns turistas. Durante o trabalho de campo vivenciei este período, tendo mesmo participado nestas negociações, uma vez que tive de ceder o meu quarto a uns turistas por alguns dias, mas os donos da casa só fizeram a proposta porque sabiam que eu não ia estar na Chã durante esse tempo, se não teriam que conversar com outras casas para solucionar a situação. Quanto aos outros dez meses do ano, os trabalhos relacionados com o turismo são escassos, podendo uma casa ou mesmo os guias turísticos ficarem durante longos períodos sem terem turistas. Esta inconstância faz com que as mais valias econômicas das atividades turísticas não sejam suficientes para os indivíduos da comunidade abdicarem das outras atividades existentes, mesmo que estas sejam menos lucrativas.

\section{As atividades turísticas e a organização familiar na Chã das Caldeiras}

É ao nível da organização familiar que se constata que as atividades turísticas são incorporadas no modo de produção existente que se baseia na economia do incerto. A escassez de recursos naturais, inclusive água, agravada pelas secas prolongadas e pelo solo pobre em várias ilhas, fazem com que exista uma grande imprevisibilidade em relação à produção agrícola e consequentemente nas subsistências das famílias. Para ultrapassar estas limitações as famílias rurais cabo-verdianas diversificam as suas actividades, não ficando depende de uma só fonte de rendimento. Para além disso a reprodução dos grupos domésticos depende da participação de todas as pessoas que fazem parte dele e das redes de vicinalidades que são estabelecidas, e como as outras atividades, os trabalhos relacionados com o turismo reproduzem a gestão de recurso mínimos, que se define pela diversificação das fontes de rendimento. Isto fica evidente nas três atividades turísticas com maior potencial de expansão, ou seja, os alojamentos, as excursões e o artesanato (Müller, 2011), que são, por norma, integradas nas atividades do grupo doméstico, permitindo assim, aos indivíduos aumentar a diversificação das suas fontes de rendimento, exemplo disto é o caso do Alcindo, um habitante da Chã, que começou por fazer artesanato quando ainda era criança de forma a ajudar a sua mãe, depois enveredou pela atividade de guia turístico, tendo conseguido, mais tarde, um contrato com uma agência turística, que lhe possibilitou trabalhar por mais tempo nesta área em comparação com a maioria dos guias da Chã, pois também realizava excursões noutras ilhas. Mais ainda, na altura do trabalho de campo concluiu a construção de uns quartos na sua residência para albergar turistas. Mesmo assim, ao longo da sua vida teve de realizar outras atividades, como o de trabalhar nas Frentes de Trabalho ${ }^{3}$, na agricultura e na pecuária, e mesmo agora, que obtém rendimentos como guia turístico e como dono de um alojamento turístico, não abdica da agricultura 
e da pecuária, tendo mesmo referido que recentemente tinha apropriado um terreno baldio e que já tinha cultivado videiras nele.

Esta diversificação das fontes de rendimento é comum nos habitantes da Chã e só é possível, porque estão integrados numa rede familiar e/ou de vicinalidade, que lhes permite desempenhar estas várias atividades. No caso do Alcindo, que vive sozinho, as atividades que desempenha dependem da participação de outras pessoas que vivem noutras casas, por exemplo, nas atividades relacionadas com o alojamento dos turistas, depende do trabalho realizado por uma das suas irmãs que vive sozinha com o seu filho e de uma cunhada que vive com o seu irmão e filhos.

A atividade de guia turístico é das poucas que permite uma maior autonomia em relação às redes familiares e de vicinalidade, todavia, esta atividade é desempenhada principalmente pelos jovens adultos do sexo masculino ${ }^{4}$, situação que está diretamente relacionada com o facto das mulheres ficarem circunscritas à casa. Isto é evidente quando olhamos para quem vende artesanato, que é o principal meio para se começar a trabalhar como guia turístico, exemplo disto, é o Alcindo, que aprendeu a falar francês na altura em que vendia artesanato e foi a partir daí que conseguiu fazer as suas primeiras excursões ao vulcão. A venda do artesanato é feita principalmente pelas crianças de ambos os sexos, que nos seus tempos livres vão para lugares estratégicos e tentam vender as peças aos turistas, mas também existem alguns adolescentes e jovens adultos, mas estes são na sua maioria do sexo masculino, isto acontece porque, durante a infância não existe uma divisão do gênero em relação às tarefas e aos espaços, situação que começa a acontecer na adolescência e que faz com que as raparigas fiquem limitadas aos espaços domésticos, enquanto que os rapazes têm a liberdade de circular na rua, que são os espaços que permitem o exercício dos trabalhos de guia turístico e da venda de artesanato.

Os jovens adultos que conseguem trabalhos como guias turísticos apresentam-se em melhores condições para obter a sua independência, pois com o dinheiro desta atividade, mesmo que esporádica, conseguem obter um rendimento acima da média, situação que fica explicita nesta passagem do meu diário de campo:

Elas começaram a falar dos jovens da Chã, mais precisamente que os trabalhadores fixos do Neves só ganham 500 escudos por dia, mas como alguns experimentaram o dinheiro obtido pelo turismo, que só uma subida ao vulcão, que dura uma manhã, é de 4000 escudos, os jovens preferem do que para o Neves. $\mathrm{Na}$ sequência disto, falaram dos proprietários, pois os grandes cobram pouco pelo trabalho, mas os jovens aceitam, pois é mais ou menos um trabalho fixo, enquanto que os pequenos pagam mais dinheiro, mas o trabalho é de curta duração.

Para além de se obter um maior rendimento, a actividade de guia apresenta outras vantagens, pois ao contrário das outras atividades, que requerem a participação de várias pessoas e onde o dinheiro obtido fica normalmente na posse dos chefes de família, no caso dos guias turísticos o trabalho é individual e o dinheiro fica com os jovens, o que lhes permite estar em melhor posição económica. Mesmo assim, o trabalho como guia turístico na Chã não altera o modo de reprodução social existente, isto verifica-se, por exemplo, na construção de casas, ou seja, apesar de terem mais meios económicos para construir uma casa, os terrenos onde vão construir são por norma cedidos pelos seus pais, mais ainda, na altura da construção da casa utilizam o djunta mon, um sistema de entreajuda amplamente utilizado em Cabo Verde, na qual um individuo convida os seus amigos e familiares para fazer um trabalho, no caso da construção de casas na Chã é comum na colocação do betão, ou seja:

"A importância social e económica atribuída pelo camponês ao djunta mon pode ser verificada pela extensão desta forma de trabalho a outros sectores produtivos e sociais como o da construção civil em que, quem está a construir, no momento de "cobrir" a sua casa (trabalho que deve ser realizado num único dia) reúne os amigos para a empreitada e garante a alimentação e as bebidas quando concluída a tarefa" (Évora, 2011: 5)

Apesar das vantagens existentes, os guias turísticos da Chã das Caldeiras não abdicam das outras actividades existentes, reproduzindo assim, o modo de produção existente baseado na transversalidade de múltiplas actividades. 


\section{A lógica de não colocar todos os ovos no mesmo cesto}

A cultura vinícola e o turismo englobam as actividades na qual as pessoas da Chã conseguem obter mais rendimentos, constituindo também um factor diferenciador em relação às outras localidades da ilha do Fogo e de certo modo do arquipélago, pois é o único lugar de Cabo Verde onde se cultiva a uva e que tem um vulcão activo. Não obstante, a lógica da reprodução de subsistência desta comunidade continua a ser mesma que os primeiros habitantes implementaram quando chegaram a Chã das Caldeiras e que não se diferencia dos outros meios rurais de Cabo Verde, ou seja:

A esmagadora maioria das famílias rurais cabo-verdianas faz a agricultura de sequeiro porque esta abre um ciclo de subsistência doméstica. Esta subsistência assenta na transversalidade de múltiplas actividades, não colocando os ovos no mesmo cesto, diversificando fontes de rendimento e recursos, numa base de complementaridade e na lógica de uma gestão de recursos mínimos. (Couto, 2010: 391-392)

A pluriactividade não se resume aos trabalhos agrícolas e turísticos, isto porque, no dia-a-dia os indivíduos arranjam diversas formas de obterem algum tipo de rendimento, como é o caso das mulheres, que compram produtos em S. Filipe e vão revender nas casas da Chã, ou então, os biscates que os homens fazem, quando conseguem trabalhar em alguma construção. Embora estas pequenas actividades façam parte dos agregados que se encontram numa situação mais vulnerável, como é o caso dos jovens adultos que construíram recentemente a sua casa, estes não podem ser analisados isoladamente, pois a sua constituição e continuidade depende das redes familiares e de vicinalidade em que estão inseridos.

A lógica da reprodução de subsistência existente na Chã tem como base a interdependência entre as pessoas e as casas, mas também, da diversidade das actividades que estes consigam realizar. Isto acontece, porque os recursos são mínimos e mesmo com as novas economias de rendimento, que têm melhorado substancialmente a vida das pessoas, também se constata que estas reiteram a economia do incerto existente, ou seja, como as culturas agrícolas de subsistência, a cultura vinícola está sujeita às secas cíclicas, todavia, as famílias utilizam algumas estratégias para minimizar os risco de perder toda a colheita, como é a articulação da pluricultura em diferentes terrenos, que é uma pratica comum no meio rural santiaguense (Couto, 2010), mas que no caso da Chã, também funciona nas alturas em que o vulcão entra em erupção, pois a lava tem tendência a cobrir somente algumas áreas da cratera e por isso se um individuo tiver mais do que um terreno em diferentes zonas, têm maiores probabilidades de não perder toda a sua propriedade.

Segundo Lopéz (2009) é o sistema de sucessão hereditário bilateral que provoca uma continua divisão das propriedades, sendo a média para cada agricultor de 3,2 explorações agrícolas. A partilha dos terrenos têm alguns critérios, ou seja, a divisão dos terrenos é feita com os herdeiros e pelo cabo chefe ${ }^{5}$, que serve de mediador, utilizando uma corda, os terrenos são divididos consoante a sua produtividade, por exemplo, se a um dos herdeiros for concedido uma área menos produtiva em relação aos outros, em termos de tamanho, o terreno deste tem de ser maior, no final da divisão, cada herdeiro ficam em posse de uma parte de cada terreno que os seus pais deixaram.

Desta divisão resulta a grande fragmentação dos terrenos da Chã, que do ponto de vista econômico parece ser contraproducente, uma vez que leva aos herdeiros a despender mais tempo do que se tivesse somente um terreno, pois têm de se deslocar para diferentes terrenos que normalmente ficam em pontos geograficamente distantes uns dos outros, mais ainda, como a área de cultivo é cada vez menor, o que seria de esperar é que a produção também fosse menor, mas isto não acontece, pois com as relações de cooperação que se estabelece entre os herdeiros e/ou outros agricultores que tenham terrenos vizinhos, os agricultores conseguem maximizar a sua produção, isto é, em termos de posse, o terreno pertence a um individuo ou a um casal, mas em determinadas alturas do ciclo agrícola a demanda de mão-de-obra é elevada e por isso a solução é feita através das várias pessoas que compõem o grupo doméstico, mas principalmente do sistema de djunta mon. Quando a pessoa não consegue manter as relações de cooperação fica numa situação desfavorável, por isso mesmo, podemos constatar que sustentabilidade da atividade agrícola é indissociável das redes de cooperação, pois sem elas, mesmo que a pessoa tenha um bom terreno não tem meios para cultivar, e é por isso mesmo que se verifica uma percentagem elevada de terrenos em boas condições para cultivo, mas que se encontram inexplorados (López, 2009).

Da mesma forma que as actividades agrícolas se caraterizam por uma grande imprevisibilidade derivada da escassez de recursos naturais e pelas secas prolongada, as actividades turísticas na Chã 
das Caldeiras também não permitem uma total autonomia, principalmente pelo numero de turistas que visitam a cratera, mesmo assim, o que se verifica é que existe uma complementaridade entre estas duas actividades, permitindo os grupos domésticos cooperarem entre si de forma a suprimir os recursos mínimos existentes.

\section{Conclusão}

A lógica da reprodução de subsistência existente na Chã tem como base a interdependência entre as pessoas e as casas, mas também, na diversidade das atividades que estes consigam realizar. Isto acontece, porque os recursos são mínimos e mesmo com as novas economias de rendimento baseadas no turismo, que têm melhorado substancialmente a vida das pessoas, também se constata que estas reiteram a economia do incerto existente. Como as culturas agrícolas de subsistência, a cultura vinícola está sujeita às secas cíclicas, todavia, as famílias utilizam algumas estratégias para minimizar os risco de perder toda a colheita, como é a articulação da pluricultura em diferentes terrenos, que é uma pratica comum no meio rural santiaguense (Couto, 2010), mas que no caso da Chã, também funciona nas alturas em que o vulcão entra em erupção, pois a lava tem tendência a cobrir somente algumas áreas da cratera e por isso se um individuo tiver mais do que um terreno em diferentes zonas, tem maiores probabilidades de não perder toda a sua propriedade. O mesmo se passa com o turismo, pois apesar das atividade turísticas apresentarem mais lucro e de existirem previsões de aumento da procura turística a cada ano, o ethos de imprevisibilidade dos habitantes continua, e por isso a estratégia dos indivíduos passa sempre pela diversificação das atividades.

\section{Epílogo}

No dia 23 de Novembro de 2014 aconteceu mais uma erupção vulcânica na Chã das Caldeiras, tendo está sido mais severa para a população, uma vez que as principais localidades (Portela e Banguaeira) foram destruídas pela lava e a população foi mais uma vez evacuada para outras localidades. Um dos temas que se colocou em vários meios de comunicação era se a população iria retornar para a Chã. Nesse mesmo sentido eu e o meu colega Samuel Weeks (2016) abordamos o tema a partir de uma comparação entre a erupção de 1995 e a de 2004, na qual prevíamos que as pessoas iriam voltar para a Chã. As nossas previsões não estavam erradas, tendo nos últimos anos várias famílias arriscado o regresso, isto apesar das autoridades proibirem.

Curiosamente, uma das diferenças entre estas duas erupções e o retorno das pessoas à Chã, consiste no facto das primeiras casas a serem contruídas após a erupção de 2014 serem para acolhimento turístico, chegando o número a ser actualmente superior ao que existia antes desta erupção:

Treze estabelecimentos de acolhimentos de turistas, com um total de 123 quartos, mais 19 unidades do que antes da última erupção, surgiram nos últimos três anos em Chã das Caldeiras para acolher o número crescente de turistas que procuraram a localidade.” (Inforpress, 2017)

Este facto demonstra a importância que o turismo tem para a população da Chã, mais ainda, tomando em conta a economia do incerto, verifica-se que ao serem deslocadas para outras localidades, as pessoas da Chã não conseguem reproduzir os modos de produção que tinham, pois é normal as redes de cooperação deixarem de existir e consequentemente não conseguirem a subsistência que tinham na Chã, por isso mesmo, apesar do risco de uma nova erupção ser elevado, as pessoas optam por regressar a Chã.

\section{Bibliografia}

Baker, Bruce

2009. "Cape Verde: Marketing Good Governance”. Africa Spectrum, 44 (2): 135-147

Bertram, Geoff

1999. “The MIRAB Model twelve years on". The contemporary Pacific: a Journal of Islands Affairs, 11

(1): $105-138$ 
Bronze, Valdevino

2007. A geografia do turismo em Cabo Verde. O desenvolvimento turístico no Parque Natural do Fogo.

Tese de licenciatura, Escola Superior de Hotelaria e Turismo do Estoril

Carvalho, Mário

2007. “Turismo em Cabo Verde: uma nova fase?". Africanidade: http://www.africanidade.com/articles/51/1/

Turismo-em-Cabo-Verde-uma-nova- fase/Paacutegina1.html (cons. 10/12/10)

Carreira, António

1983. Migrações nas ilhas de Cabo verde. Praia: Instituto cabo-verdiano do livro

1984. Cabo Verde: Aspectos Sociais. Secas e fomes do século XX. Lisboa: Ulmeiro

Clarke, Jackie

1997. "A framework of approaches to sustainable tourism". Journal of Sustainable Tourism. 5 (3): 224-233

Cole, Stroma

2007. "Beyond authenticity and commodification". Annals of Tourism Research. 34 (4): 943-960

Couto, Carlos

2010. Incerteza, adaptabilidade e inovação na sociedade rural da ilha de Santiago de Cabo Verde. Lisboa:

Fundação Calouste Gulbenkian e Fundação para a Ciência e a Tecnologia.

Crick, Malcolm

1989. "Representations of International Tourism in the Social Sciences: Sun, Sex, Sights, Savings, and

Servility". Annual Review of Anthropology, 18: 307-344.

Estevão, João

2001. As Pequenas Economias Insulares e as Condições do Desenvolvimento Económico. Cultura,

Número Especial, Setembro, 71-78

Évora, Iolanda

2011. "Djunta-mon em três tempos: pós-independência, imigração e transnacionalismo. Aspectos da experiência associativa cabo-verdiana". Centro de Estudos sobre África e Desenvolvimeto. http:// pascal.iseg.utl.pt/ cesa/files/Doc_trabalho/96.pdf (cons. 23/02/18)

Expresso das ilhas

2009. "Chã das Caldeiras: Vulcão garante o sustento dos cerca de 750 habitantes". Expresso das ilhas. http://www.expressodasilhas.sapo.cv/pt/noticias/detail/id/12031 (cons. 10/11/10)

Ferreira, Eduardo

2008. O Turismo Sustentável como factor de desenvolvimento das pequenas economias insulares: o caso de Cabo Verde. Lisboa: Edições Universitárias Lusófonas.

Filho, João

1997. O corpo e o pão. O vestuário e o regime alimentar cabo-verdianos. Oeiras: Câmara Municipal de Oeiras

Gardner, Katy; Lewis, David

1996. Anthropology, development and the post-modern challenge. London: Pluto Press

Higgins-Desbiolles, Freya

2010. "The elusiveness of sustainability in tourism: The culture-ideology of consumerism and its implications". Tourism and Hospitality Research. 10 (2): 116-129

Inforpress

2017. Ilha do Fogo: 13 estabelecimentos de acolhimento de turistas com 123 quartos surgiram na Caldeira nos últimos três anos. http://www.inforpress.publ.cv/ilha-do-fogo-13-estabelecimentos-acolhimento-turistas-123-quartos-surgiram-na-caldeira-nos-ultimos-tres-anos/

(cons. 29/11/17)

Kadt, Emanuel

1979. Tourism, Passport to Development? - perspectives on the social and cultural effects of tourism in developing countries. Oxford: Oxford University Press.

Leyens, Teresa

2002. Biodiversidade da prevista área protegida na Ilha do Fogo / Cabo Verde: Elaboração de programas e medidas para a sua conservação sustentável. Eschborn: Deutsche Gesellschaft für Technische Zusammenarbeit (GTZ)

Lobo, Andréa

2006. Tão longe e tão perto. Organização familiar e emigração feminina na ilha da Boavista - Cabo Verde. Tese de Doutoramento, PPGAS do Departamento de Antropologia da Universidade de Brasília, Brasília : Universidade de Brasília. 
López, Alejandro

2009. Desarrollo de una metodología para elaborar un catastro Agroforestal en la Isla de Fogo (Cabo Verde). Dissertação em engenharia agrónoma, Escuela Técnica Superior de Ingenieros Agrónomos y de Montes, Universidad de Córdoba

Lu, Jiaying, Nepal, Sanjay

2009. "Sustainable tourism research: an analysis of papers published in the Journal of Sustainable Tourism”. Journal of Sustainable Tourism. 17 (1): 5-16

Meintel, Deirdre

1984. Race, Culture and Portuguese Colonialism in Cabo Verde. Syracuse: Maxwell School of Citizanship and Public Affairs

Milano, Claudio; Gascón, Jordi

2017. "Introducción. Turismo y sociedad rural, o el extraño caso del doctor Jekyll y Mr. Hyde". Em Gascón, Jordi e Milano, Claudio (coord.), El turismo en el mundo rural. ¿Ruina o consolidación de las sociedades campesinas e indígenas? (pp. 5-22) http://pasosonline.org/Publicados/pasosoedita/ PSEdita18.pdf (cons.31/02/18)

Moran, Emilio

1982. "The Evolution of Cape Verde's Agriculture." African Economic History. 11: 63-86

Müller, Karina

2011. The Role of Tourism in the Natural Park of Fogo. Analysis and Recommendations for a sustainable development. Dissertação de licenciatura, Faculty of Geography of the University of Trier.

Pelling, Mark

2008. “The Rio Earth Summit”. Em Desai, Vandana, Potter. Robert. (eds) The companion to development studies. ( pp. 288-293) Londres: Hodder Education

Redclift, Michael

2008. "Sustainable development". Em Desai, Vandana, Potter, Robert. (eds.) The companion to development studies. (pp. 279-282) Londres: Hodder Education

República de Cabo Verde

2009. Plano de Gestão do Parque Natural do Fogo. Praia: Ministério do Ambiente, Desenvolvimento Rural e Recursos Marinhos Direcção-Geral do Ambiente

Ribeiro, Orlando

1998. A ilha do Fogo e as suas erupções . Lisboa : Edição da Comissão Nacional para as Comemorações dos Descobrimentos Portugueses

Rodrigues, Jaime; Fattori, Paolo

2008. Chã das Caldeiras: Memória do Passado e Expectativas do Futuro. Praia: COSPE

Rodrigues, Orlando

2010. "Chã das Caldeiras: Depositário do mistério das origens do arquipélago." Fragata, Julho/Agosto: 24-29.

Santos, Bruna

2008. "O desafio de um Turismo Sustentável Vs A ameaça de um Turismo Insustentável". Visão contacto: http://visaocontacto.blogs.sapo.pt/74887.html (cons. 10/11/2010)

Santos, Maria

2009. Turismo em Cabo Verde: Um estudo exploratório. Dissertação de Mestrado, Instituto de Ciências Sociais da Universidade de Lisboa

Smith, Valene,

1989. Hosts and Guests - The Antropology of Tourism. Filadélfia: University of Pennsylvania Press.

Urry, John

1990. The Tourist Gaze - leisure and travel in contemporary societies. London: Sage Publications.

Wall, Geoffrey

1997. “Is Ecotourism Sustainable?”. Environmental Management. 21 (4): 483-491

Watters, Ray

1987. "MIRAB Societies and Bureaucratic Elites". Em Hooper, Tony (ed.), Class and Culture in the South Pacific (35-54). Suva: University of the South Pacific

Weeks, Samuel; Popinsky, Vitor

2016. "Symbolism and Resilience in the Aftermath of a Destructive Volcanic Eruption". Anthropology Now. 8 (2): 57-68 


\section{Notas}

1 Os dados aqui apresentados têm como base o trabalho etnográfico que realizei entre janeiro de 2012 e março de 2013 na Chã das Caldeiras, fincanciado pela Fundação para a Ciência e Tecnologia (SFRH/BD/70507/2010)

2 Para além do vulcão do Fogo, a própria população da Chã também tem sido utilizada em propagandas turística, mais precisamente, porque grande parte da população tem cabelos loiros, olhos claros (traços físicos que se diferenciam da maioria dos cabo-verdianos ) e serem descendentes de um conde francês, chamado Armand Montrond.

3 Termo utilizado pelos habitantes para se referirem tanto às Frentes de Alta Intensidade de Mão-de-Obra (FAIMO) designação utilizada na década de 90 e antes na década de 80 eram denomindas por AIMO (Alta Intensidade de Mão-de-obra) para as politicas governamentais, que começaram ainda no período colonial e continuaram com a independência nacional, e onde o governo cabo-verdiano com a ajuda financeira e alimentar internacional criaram postos de trabalho de forma a suprimir as crises cíclicas.

4 Na altura do trabalho de campo só existia uma mulher guia turístico.

5 Individuo que a população elege para resolver conflitos entre os habitantes, normalmente alguém com uma certa idade e que seja respeitada pela maioria das pessoas. 